\title{
Cooperação internacional, parcerias acadêmicas e afeto na perspectiva Sul-Sul
}

\author{
International Cooperation, Academic Partnerships, and Affection
}

in a South-South Perspective

Laura Moutinho' (iD 0000-0001-6479-2711

'Universidade de São Paulo, São Paulo, SP, Brasil. 05508-090 - ppgas@usp.br

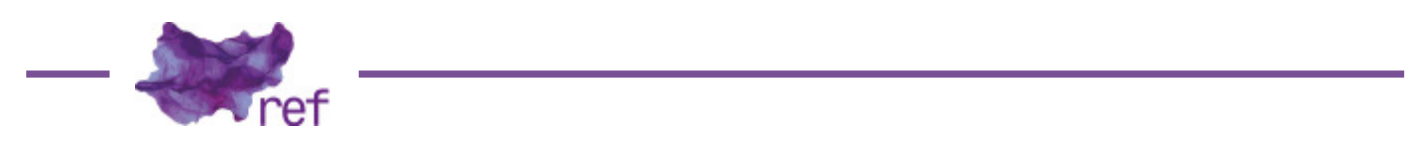

Sempre me impressionou a permanente e trágica ingerência da minoria racista da África do Sul no meu país, onde, sobretudo na década de 1980, incontáveis moçambicanos viram o rumo das suas vidas desviado ou, simplesmente, deixaram de existir, por vontade e por ordem dos defensores do apartheid. Lília Momplé, em Neighbours

São com estas enfáticas palavras que a escritora moçambicana Lília MOMPLÉ (2008) inicia Neighbours, livro de ficção baseado em fatos reais que narra histórias interligadas de três famílias residentes de Maputo, ao longo de uma única noite. O título, inspirado em uma obra de arte que evocava a vizinhança com a África do Sul e o apartheid, foi escolhido por expressar a "sensação de constante asfixia e extrema vulnerabilidade perante forças [...] poderosas e hostis" (MOMPLÉ, 2008, p. 05). Esta não é uma percepção isolada. Ainda que Moçambique e África do Sul tenham histórias coloniais diferenciadas (e em parte radicalmente distintas, se nos ativermos, por exemplo, à questão racial), a relação entre os dois países sempre foi estreita e complexa: desde o apoio dado pela África do Sul à Renamo contra a Frelimo' na guerra civil, também conhecida como "guerra de 16 anos", que assolou Moçambique após a independência de Portugal, em 1975 (José Luís CABAÇO, 2009), passando pelo refúgio que Moçambique ofereceu aos que lutaram contra o apartheid ${ }^{2}$ (como Ruth First, Albie Sachs, entre outros). O acesso ao sistema de saúde sulafricano pelos moçambicanos também é um ponto de conexão: são muitos os que pegam ônibus em Maputo para se tratar em hospitais sul-africanos, especialmente em Johannesburg. Mesmo que com distintos propósitos e atuações, homens e mulheres cruzavam e ainda cruzam a fronteira da África do Sul e Moçambique para aquisição de moeda, bens de consumo, trabalho nas minas (que vêm desde o século XIX), atuação em setores formais e informais como a construção civil. A rota migratória e de comércio tem outras características importantes: são frágeis os laços sociais que os unem. A maioria dos moçambicanos que migra para Johannesburg até se dirige para casa de parentes e amigos, num movimento similar ao de outros grupos, mas diante das difíceis condições de vida, não permanecem nessas primeiras habitações. Dominique VIDAL (2009) fala de uma "falta de confiança nas relações sociais entre" os que se aventuram na direção de uma vida melhor na África do Sul (p. 14). A experiência de racialização que existe em Moçambique, mas de modo diferente, é outro ponto importante num percurso que ganhou novos sentidos com a democratização nesses contextos: frequentemente xenofobia - que acometeu particularmente

\footnotetext{
* Seção temática organizada por Laura Moutinho e Esmeralda Mariano.

' A Renamo (Resistência Nacional Moçambicana) lutou após a independência de Moçambique contra a Frelimo (Frente de Libertação Moçambicana), organização de esquerda que negociou com Portugal a independência, após uma longa sequência de conflitos armados. A Renamo recebeu apoio da África do Sul do apartheid, da minoria branca do atual Zimbábue e de outras forças tidas como conservadoras, que queriam desestabilizar o país e impedir - avanço do socialismo no continente africano. Essa disputa levou à guerra civil, que devastou Moçambique, de 1976 a 1992. Ambas as organizações são, atualmente, no regime democrático presidencialista, partidos políticos. ${ }^{2} \mathrm{O}$ apartheid foi um regime de segregação racial implementado na África do Sul em 1948, que concedia direitos constitucionais diferenciados com base na raça e no racismo, privilegiando a minoria branca que comandou o país até 1994, quando se instituíram as eleições gerais e democráticas que levaram à vitória do líder de oposição Nelson Mandela.
} 
migrantes de Zimbábue e Moçambique - é um termo intercambiável nas narrativas sobre exclusão e discriminação.

Desde o período socialista, as mulheres também mantinham atividades visando à geração de renda, algumas delas chamadas de mukheristas: abasteciam o mercado com produtos sulafricanos que eram escassos em Moçambique (Luiz Henrique PASSADOR, 2011). Esta é uma atividade que se expandiu e está mais diversificada, mas que retém a característica de ser predominantemente feminina, como poderá ser visto nesta Seção Temática em texto fruto do trabalho etnográfico realizado no acompanhamento dessa rota de comércio (Rita Simone LIBERATO et al., 2019).

De fato, faz-se necessário ressaltar, a relação entre a África do Sul e os demais países vizinhos não foi igualitária. Wolfgang DÖPCKE (1998) recorre a expressões como "imperialismo sulafricano" e "colonial" ao qualificar as ações políticas e econômicas sul-africanas que visavam à manutenção do controle e à sua hegemonia na África Austral. Nas palavras do autor:

\begin{abstract}
O intercâmbio na região é caracterizado como "colonial", destacando-se o fato de que a África do Sul considera os países vizinhos como "mercado natural" para os produtos de sua indústria secundária. Por outro lado, o termo amplamente usado para caracterizar a situação dos Estados vizinhos em relação à África do Sul é dependência. Nos anos 80 , o grau de dependência para com a África do Sul variava muito entre os Estados individuais: de dependência e vulnerabilidade absoluta (no caso dos BSL-states 10 e Namíbia), dependência média (Zimbábue, Moçambique, Zâmbia) até dependência relativamente baixa (Angola) (p. 137).
\end{abstract}

Foi somente no início da década de 1990, com o fim do apartheid e a democracia, que a África do Sul redefiniu sua atuação política regional, marcada pela desestabilização dos países vizinhos e por ações de guerra, mesmo que não declaradas oficialmente.

O projeto de investigação que desenvolvemos (que resultou na organização de uma rede internacional, cujos frutos começam aqui a ser disponibilizados ao público) se inscreve, justamente, no interior de um quadro amplo e complexo relativo à experiência de redemocratização em curso na África do Sul e em Moçambique, tendo ainda o Brasil como contraponto comparativo ora explícito ora implícito.

O longo caminho que os países africanos percorreram desde a dura luta de resistência ao colonialismo até os embates contemporâneos nas áreas da cultura, da economia e da política deve ser observado em perspectiva. O olhar contrastivo com o Brasil incentiva-nos a refletir sobre uma dinâmica que obedece também a amplos fluxos globais, a fim de que entendamos adequadamente os desafios enfrentados hoje por aqueles países, ao mesmo tempo que possamos pensar as possibilidades que se apresentam de ultrapassar certos impasses e formas perenes de produção de desigualdades.

\title{
Algumas palavras sobre o processo e 0 apoio financeiro
}

Parte da rede que constituiu esta pesquisa iniciou sua interlocução através de outro projeto comparado internacional, financiado pela Fundação Ford e pelo CNPq, "Relations among 'race', sexuality and gender in different local and national contexts", ${ }^{3}$ que cotejou Brasil (Rio de Janeiro e São Paulo), África do Sul (Cape Town e Johannesburg) e Estados Unidos (San Francisco e Chicago), sobre juventude e interseccionalidade nesses seis contextos. Ainda que a pesquisa tenha sido finalizada em 2010, com a publicação de dois dossiês (ver Laura MOUTINHO; Sergio CARRARA, 2010a; 2010b), ela foi um momento de maturação da discussão que se segue. Notamos, ao longo do processo, como era importante a existência de uma troca anterior de ideias e textos. A parceria anteriormente estabelecida não somente formou alunos, oportunizou pesquisas e abriu a interlocução entre os professores e as instituições envolvidas, como, igualmente, pavimentou um espaço de confiança que permitiu este novo empreendimento em condições geopolíticas mais igualitárias. Diversas pessoas que desempenharam funções no projeto que se encerrou em 2010 seguiram trabalhando juntas neste, que concluímos em 2018, bem como trouxeram consigo ainda novas parcerias.

Além disso, desde a experiência anterior, tínhamos a intenção de operar outro locus de investigação. De fato, desde a primeira experiência já havia sido colocado em perspectiva a compreensão de que o Hemisfério Norte (no caso, os Estados Unidos) era tomado como polo produtor de teoria e o Sul (naquela oportunidade, Brasil e África do Sul) receptor. Face a essa lógica, pudemos rever categorias de entendimento que olham para o Sul sob o signo da carência

\footnotetext{
${ }^{3}$ Esse projeto foi concebido originalmente por Laura Moutinho, Elaine Salo, Simone Monteiro, Cathy Cohen, Omar Ribeiro Thomaz e Rafael Diaz. A pesquisa foi desenvolvida por nove diferentes centros de estudos e pesquisa: USP (São Paulo), CLAM/IMS/UERJ (Rio de Janeiro), CEBRAP (São Paulo), IOC/FIOCRUZ (Rio de Janeiro), SFSU/CRGS (San Francisco), Center for the Study of Race, Politics and Culture (Chicago), AGI/UCT (Cape Town), WITS e OUT (Johannesburg). A investigação foi realizada por Laura Moutinho (coordenação geral), Simone Monteiro (coordenadora local - Rio de Janeiro), Julio Simões (coordenador local - São Paulo), Elaine Salo (coordenadora local - Cape Town), Brigitte Bagnol (coordenadora local - Johannesburg), Cathy Cohen (coordenadora local - Chicago) e Jessica Fields (coordenadora local - San Francisco).
} 
e da falta (MOUTINHO; CARRARA, 2010c). Na literatura internacional, raramente Moçambique, África do Sul e Brasil compõem projetos comparados de pesquisa. Esta possibilidade nos foi facultada justamente pelo formato do edital PROÁFRICA/CNPq.

A produção sistêmica de subalternidades engendra formas diversas de resistências e de lutas por reconhecimento que podem ser sintetizadas no seguinte trinômio: ações estatais, movimentos sociais e subjetividades. Assim, propusemo-nos a investigar até que ponto essas três dimensões se cruzam, ou poderiam se cruzar, nas situações sociais dos contextos em tela. O projeto apresentado contemplou assim as três áreas de conhecimento priorizadas no edital: inclusão social, saúde pública e segurança alimentar.

A proposta inicial contou com um grupo que foi sendo ampliado ao longo do processo de realização da pesquisa. Iniciamos com coordenação geral de Laura Moutinho (USP) e com pesquisadoras e pesquisadores seniores de diferentes instituições: Esmeralda Mariano (UEM), Lilia Schwarcz (USP), Paulo Neves (UFS e UFABC), José Ricardo Ayres (USP), Brigitte Bagnol (WITS), Rita Simone Liberato (UFS). Ao longo do processo, com a formação da rede e demandas geradas pelo próprio desenvolvimento de pesquisa (como no caso do campo da deficiência, não previsto na proposta original), foram incorporadas Carla Braga (UEM), Pedro Lopes (USP), Denise Dias Barros (USP), Solange Rocha (UCT e NEPPS/UFPE), Susan Holland-Muter (UCT) e Isabel Noronha (CES - Centro de Estudos Sociais/Coimbra). Houve ainda o apoio, a colaboração e/ou interlocução de diferentes formas com Zethu Matebeni (UCT), Colin Darch (UCT), Shaun Vilojen (SUN), Sherine Van Wyk (SUN), Anthea Lesch (SUN), Bernard Dubbeld (SUN), Fernanda De Oliveira Pinto (WCU), Deborah Diedericks (Khululeka Grief Support), Suely Messeder (UNEB), Julio Simões (USP) e Luiz Henrique Passador (Unifesp). Contamos também, em distintos momentos, com alunos dos três diferentes países ao longo do percurso: Denise Pimenta (USP/Brasil); Marcio Zamboni (USP/Brasil); Gabriela Calazans (USP/Brasil); Thais Tiriba (USP/Brasil); Isabel Zanzotti de Oliveira (USP/Brasil); Anésio Manhiça (UEM/Moçambique); Phillip Leite (USP/Brasil); Celso Junior (USP/Brasil), Theo Neves (Paris 7/Diderot/França); Courtney Koopman (UCT/África do Sul); Carolina de Campos Tornich (USP/Brasil); Adrian Van Wyk (Stellenbosch University/SUN/África do Sul).

O "Programa de cooperação temática em matéria de ciência e tecnologia" - PROÁFRICA foi criado por intermédio da Portaria MCT n. ${ }^{\circ} 363$, de 22 de julho de 2004. De 2005 a 2010 foram lançados cinco editais e financiados 190 projetos. Este projeto foi selecionado em 2015 e implementado em 2016. Somente mais um edital foi lançado depois disso e o programa foi descontinuado, até onde se sabe (ver PROÁFRICA no Portal do CNPq).

Tais editais permitiram a criação de redes e desenvolvimento de pesquisas com países africanos, como as que atualmente celebramos. Porém, se, de fato, o grosso dos financiamentos do CNPq/Capes continuou sendo em direção aos países do Norte (ver mapa adiante), devo destacar que estes significativos incentivos nos permitiram ampliar as fronteiras do fazer científico, repensar e, em parte, reconfigurar a geopolítica do conhecimento tanto interna quanto externamente e, nesse sentido, ampliar a interlocução com a inserção do Brasil nesse cenário.

O seguinte mapa, do Sistema de Informações Georreferenciadas da Capes (GEOCAPES), descreve a distribuição de bolsas para estudos e formação no exterior. Nota-se que a maior parte dos apoios para formação e/ou qualificação de novos profissionais foi para o Hemisfério Norte, notadamente, Estados Unidos, Canadá e diversos países da Europa Ocidental (de 179 a 6.064 bolsas por país em 2016, representadas pela cor vermelha no mapa), seguidos por China, Japão, Austrália, Argentina, Chile, México, Moçambique e Noruega (entre 13 e 174 bolsas por país no mesmo período, representadas em amarelo). Foram significativamente menores os recursos destinados a países da África, Índia e América Latina (Colômbia, Bolívia, Paraguai, Uruguai, Cuba, Costa Rica, África do Sul, Angola, Nova Zelândia, Polônia e Finlândia, entre três e 12 bolsas, em azul no mapa, e Peru, Egito, Índia e Kenya, entre uma e duas bolsas, em verde).

Os dados anteriores são de 2016, mesmo ano em que o apoio a pesquisas e formações de redes com países da África foi descontinuado. Nota-se também, em consultas no mesmo site, uma brusca diminuição de bolsas concedidas: se, em 2016, foram distribuídas de 179 a 6.064 bolsas para países do Hemisfério Norte, em 2018 houve uma drástica redução do fomento, com a distribuição de 60 a 2.005 bolsas para as regiões mais procuradas. Não há informações disponíveis sobre os 11 anos de vigência do Edital PROÁFRICA/CNPq, entretanto, nota-se sua importância na criação de redes Sul-Sul e na ampliação do espectro de atuação da ciência brasileira.

Um importante resultado do fortalecimento das redes que a pesquisa ocasionou, que não aparece textualmente nos artigos que compõem o dossiê, mas cumpre sinalizar, foi 0 estabelecimento de parcerias institucionais, abrindo portas para a manutenção dessas trocas, que sofreram significativo abalo com os cortes de financiamento por que temos passado: três acordos de cooperação internacional foram estabelecidos com a FFLCH/USP, instituição que sediou a pesquisa, incluindo alunos, professores e funcionários, três com universidades da África do Sul, Stellenbosch University, Wits University e Western Cape University. Outros estão em andamento, bem como a renovação da parceria com a Universidade Eduardo Mondlane, em Moçambique. Ainda 
Mapa - Distribuição de Bolsistas da CAPES no Exterior - 2016

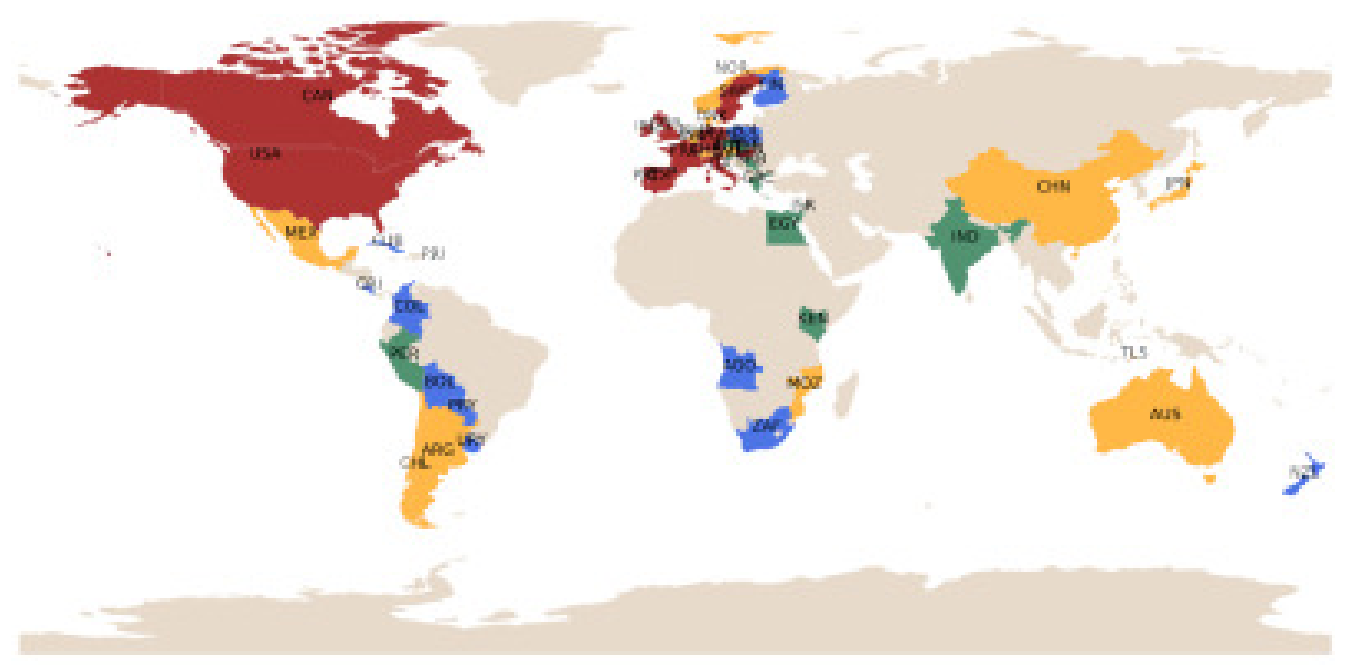

Fonte: GEOCAPES, 2017.

\section{Legenda}

De 1 até 2 (verde)

De 3 até 12 (azul)

De 13 até 178 (amarelo)

De 179 até 6.064 (vermelho)

\#PraCegoVer Imagem capturada do sistema de informações georreferenciadas da CAPES, que descreve a distribuição de bolsas no exterior por continentes e países. A legenda mostra que em 2016 foram distribuídas 6.064 bolsas. Destas, de 1 até 2 foram para Egito, Índia e Quênia (em verde no mapa). De 3 até 12 bolsas foram para Angola, África do Sul, Uruguai, Paraguai, Bolívia, Colômbia, Polônia e Finlândia (em amarelo no mapa). De 13 até 178 foram para China, Japão, Austrália, Nova Zelândia, Argentina, Chile e México (em azul no mapa). Em vermelho no mapa é assinalada a distribuição de 179 até 6.064 bolsas. Todas no hemisfério norte: Canadá, Estados Unidos, Suécia, Grã-Bretanha, Irlanda, Alemanha, França, Portugal, Itália e Hungria.

como consequência dos diálogos tecidos e do enorme esforço de construção de uma rede internacional, algo que leva um tempo significativo de gestação, foi estabelecido um acordo com a Portland University, nos Estados Unidos, e outros três estão em andamento. Nesse cenário, o Brasil tanto ampliou a rede com universidades renomadas como procurou auxiliar na tentativa de implementação de áreas com pouca tradição - como algumas conversas iniciais estabelecidas no sentido de criar uma área de antropologia visual na Universidade Eduardo Mondlane.

Internamente, a instituição que coordenou o projeto, sediado no Departamento de Antropologia, ampliou o campo de interlocução com a área da saúde - a Medicina Preventiva da USP, com a UNEB, na Bahia, a Universidade Federal do Sergipe (UFS) - com quem estamos construindo um acordo de cooperação nacional -, o SESC de São Paulo e o tradicional Centro de Estudos Africanos (CEA/USP). Diálogos foram viabilizados com o Departamento de Antropologia da UnB e o Centro de Estudos Afro-Orientais da UFBA, especialmente quando do simpósio que organizamos junto à Associação Brasileira de Antropologia (ABA). Uma série de encontros, intitulada "Olhares cruzados para a África: trânsitos e mediações", ocorreu ao longo de cerca de 10 dias, tendo se dividido entre reuniões em João Pessoa (UFPB, 30 a RBA, organizado por Laura Moutinho, USP, e Andrea Lobo, UnB) e em São Paulo (USP/PPGAS). O simpósio contou com apoio da FAPESP (Processo número 16/09840-0), da ABA e do projeto PROÁFRICA/CNPq, resultando ainda na publicação de um dossiê na Revista de Antropologia (MOUTINHO; Wilson TRAJANO FILHO; Andrea LOBO, 2017) e outro na Cadernos de Campo: Revista de Ciências Sociais (Denise PIMENTA; MOUTINHO, 2017).

Uma parte dos textos que ora disponibilizamos foi apresentada e discutida em duas outras ocasiões. A primeira, no $3^{\circ}$ workshop da pesquisa, que organizamos na University of Cape Town, em março de 2018, e a segunda, no seminário final, em novembro de 2018 , que recebeu o mesmo nome do projeto, "Seminário Final - Vizinhanças nas entrelinhas: alianças e conflitos, trocas (des)iguais e cooperação na África Austral e Brasil", realizado em parceria com o Centro de Estudos Africanos (CEA) da USP, o Programa de Pós-Graduação em Antropologia (PPGAS/USP) e o SESCFormação/SP. 
Esses são alguns dos resultados visíveis desses quase três anos de uma pesquisa comparada internacional que investiu na formação de redes, envolvendo colegas de diferentes países e instituições, viabilizada especialmente pelo financiamento do edital PROÁFRICA/CNPq, mas também com apoio da FAPESP, da USP, da FAPITEC-SE e do SESC-Formação/SP, que contribuíram de diferentes formas e em distintos momentos. A Capes é também um apoio a ser registrado, pois ofereceu bolsas de doutorado e doutorado sanduíche que em muito beneficiaram o processo mais amplo da pesquisa. Em resumo, não se faz ciência e nem se constrói um campo de interlocução internacional sem um grande esforço, sem financiamento, apoio e incentivos institucionais.

\section{O que e como se comparou?}

A comparação, que funda a empresa antropológica, é um tema espinhoso. Não existe um frame sistematizado a esse respeito (Ann Laura STOLER, 2002). Havia enfrentado essa questão inicialmente na pesquisa para minha tese de doutorado (MOUTINHO, 2004). Em Razão, Cor e Desejo, ao cotejar o Brasil e a África do Sul em relação à gestão da miscigenação, recorri a uma estratégia que visava à qualificação das ideias de "separação" e "mistura", buscando semelhanças (e, sim, há semelhanças entre a África do Sul do apartheid, o Brasil "da miscigenação" e o racismo que constitui esses dois contextos) e diferenças na regulação da sexualidade e do gênero através da raça e do racismo. A sociologia quanti e qualitativa, a historiografia clássica, romances e peças teatrais sul-africanas e brasileiras, o mapeamento e análise de processos criminais contra casais e amantes inter-raciais na África do Sul, bem como o trabalho de cunho etnográfico, formaram o amplo quadro da pesquisa. De fato, ao operar com a categoria raça e as relações raciais, ou seja, relações sociais entre brancos, negros, mestiços em perspectiva interseccional, procurei trazer a África do Sul para um campo de análises que se construiu no Brasil desde o início de modo comparado em relação aos Estados Unidos. Observar comparativamente as lógicas coloniais portuguesas, holandesas e inglesas de regulação e gestão da raça e do racismo - que foi gestado no Brasil numa política autofágica da miscigenação e, nas colônias holandesas e britânicas, a partir de políticas segregacionistas - permitiu encontrar surpreendentes paralelos.

No projeto anteriormente mencionado, "Relations among 'race', sexuality and gender in different local and national contexts", que articulava, em diferentes cidades e países, juventude e marcadores sociais da diferença (raça, sexualidade e gênero, interseccionados com o acesso e os cuidados com a saúde e diferenciais de renda, bens e status), entendemos que, nos três contextos nacionais, havia algo que se poderia nomear como raça/racismo, produzindo diferenças e desigualdades, quando articulados à sexualidade e ao gênero, ainda que o sentido dessa ideia e sua forma de operar fossem distintas nos três contextos nacionais. Elaboramos coletivamente um protocolo de pesquisa para as seis cidades que compuseram a pesquisa. Primeiramente, foram realizados mapeamentos e pesquisas etnográficas em locais de sociabilidade juvenil que agregassem grande diversidade. Após essa fase, selecionamos 24 pessoas para entrevistas em profundidade e aplicamos posteriormente 48 questionários fechados, que funcionaram como fonte de informação suplementar e controle do corpus de material levantado. Partia-se do princípio de que esses marcadores sociais da diferença articulados incidiam sobre a vulnerabilidade dos indivíduos com relação às DSTs/Aids bem como sobre a construção de si e as experiências cotidianas de exclusão.

A pesquisa ora em foco, "A vizinhança nas entrelinhas" ${ }^{4}$, foi um empreendimento elaborado no interior do chamado Sul Global. Há pontos de inflexão constitutivos desse processo. O primeiro deles se refere ao lugar e à posição da metrópole e do Norte nesse campo de relações cruzadas: a parte austral da África foi entendida como uma região com dinâmicas próprias. Nesse sentido, procuramos deixar como pano fundo as influências (e diferenças) coloniais e históricas para focar na experiência de redemocratização na África do Sul e em Moçambique, tendo ainda o Brasil como contraponto comparativo, ora explícito ora implícito, no sentido de dar inteligibilidade ao diálogo Sul-Sul.

Assim, mesmo sendo contempladas, não foram apenas as diferenças de lugar e ação dos impérios português, britânico ou mesmo holandês o foco direto de nosso trabalho. Nas diversas escalas de articulação entre o global e o local, interessou-nos deslocar a análise de certas rubricas, às vezes excessivamente homogeneizadoras, no sentido de compreender processos adjacentes de relocalização.

Esse olhar cruzado buscou afastar-se da produção de representações icônicas e literalistas que dificultam (e às vezes impossibilitam) estilos figurativos mais sensíveis que estimulem um jogo identitário mais flexível e plural, ao estabilizar convenções e modos de representação específicos (MOUTINHO; TRAJANO FILHO; LOBO, 2017).

Interessou-nos investigar o processo de inflexão iniciado com a adoção de novas constituições, em 1996 na África do Sul, em 1988 no Brasil e, no caso moçambicano, em 1975 (Independência), 1990 e 2004. Trata-se de processos de democratização com influências evidentes na (re)distribuição, sempre desigual, do poder, tanto no modo como algumas minorias e grupos subalternizados foram e vêm sendo representados e ganhando voz no debate público, quanto na forma como esses 
Estados nacionais vêm se relacionando com tais grupos, a exemplo dos casos dos negros e homossexuais na África do Sul (e mesmo no Brasil) e dos pobres e da autoridade tradicional em Moçambique.

"Herança colonial confrontada: reflexões sobre África do Sul, Brasil e Estados Unidos" abre essa sequência de reflexões abordando um certo momento conjuntural compartilhado pelo Sul Global e países do Norte. Paulo Sérgio da Costa Neves, Laura Moutinho e Lilia Schwarcz se debruçam sobre um fenômeno desafiador, que foi detonado em 09 de março de 2015, quando centenas de estudantes se mobilizaram para exigir a retirada da estátua de Cecil Rhodes, homem de negócios e uma referência colonial de grande importância no sul da África, da prestigiosa University of Cape Town (UCT), na África do Sul - um protesto que reverberou na Inglaterra. Em maio desse mesmo ano, após fortes mobilizações e debates, a Universidade Federal de Goiás (UFG) foi a primeira universidade do Brasil a implementar reserva de vagas para indígenas, afrodescendentes e pessoas com deficiência em cursos de pós-graduação. Meses depois, em novembro, estudantes da Princeton University ocuparam a reitoria exigindo que fosse removido de um dos prédios do campus o nome de Woodrow Wilson, defensor da segregação dos negros no sul dos Estados Unidos. A força desses fenômenos é analisada como parte de demandas decoloniais, com dimensões globais e locais que evidenciam um cenário que disputa memórias nacionais, reconhecimento e princípios de justiça articulados a uma nova gramática moral.

Em "Deficiência como categoria do Sul Global: primeiras aproximações com a África do Sul", Pedro Lopes se debruça sobre a temática da deficiência na África do Sul, a partir da reflexão sobre o disability grant - um benefício para pessoas com deficiência que não possam trabalhar. Também nesse cenário, a África do Sul aparece encetando uma política de vanguarda no campo dos direitos humanos. Ainda que pouco conhecida no Brasil, a tradição sul-africana traz importantes aportes para o campo da deficiência desde o Sul Global, com diálogo estreito com os Estados Unidos, mas confrontando a articulação entre deficiência e pobreza, num movimento de coprodução de aspectos raciais, espaciais e políticos.

Em "Soberania Alimentar no Machimbombo e na aldeia: gênero na perspectiva Sul-Sul", são cotejados os olhares de mulheres do Sul Global, tendo como marco de análise a soberania e a Segurança Alimentar e Nutricional (SAN). Ao longo da pesquisa, Rita Simone Liberato, Laura Moutinho, Isabel Noronha e Brigitte Bagnol notaram a importância das relações de gênero em perspectiva interseccional em dois cenários nacionais distintos tanto no que tange à experiência etnográfica quanto à formulação de políticas. Percorre-se, assim, o ponto de vista das mukheristas, nome pelo qual são chamadas as mulheres moçambicanas que fazem o comércio entre Maputo (Moçambique) e Johannesburg (África do Sul) e as experiências de mulheres da aldeia Cinta Vermelha-Jundiba, que vivem na região do semiárido, no Vale do Jequitinhonha, no Brasil: capulanas moçambicanas, sementes do semiárido, comércio, perdas e muita desigualdade social nutrem a reflexão sobre o acesso a alimentos e à saúde em perspectiva comparada.

Com a antropóloga moçambicana Carla Braga, a leitora ou leitor poderá se manter no universo da Segurança Alimentar e Nutricional com ênfase, entretanto, no modo como esta é afetada pela epidemia do HIV-Aids em Moçambique. A partir de um trabalho etnográfico realizado nas províncias de Manica e Maputo, a autora oferece reflexões sobre a dinâmica e os desafios globais da epidemia em "'Machamba não é trabalho!': HIV/SIDA e Produção Agrícola no centro de Moçambique". O cenário descrito é dramático: a invisibilidade da agricultura familiar e a dificuldade de diversificação de meios de sustento, em especial em relação às mulheres, colocam empecilhos para que se cumpram os requisitos da terapia antirretroviral e prossigam seus tratamentos.

Thais Tiriba percorre um cenário moral controverso no Brasil e na África do Sul ao perscrutar os valores e representações dos chamados sugar relationships, relacionamentos intergeracionais que são estabelecidos pela mediação de páginas na internet e aplicativos. No artigo "Sugar relationships: sexo, afeto e consumo na África do Sul e no Brasil", regimes morais e legais de regulação da sexualidade são cotejados a partir de intercâmbios de dinheiro, presentes, afetos e sexo.

Susan Holland-Muter apresenta uma cidade que retém muito da dinâmica do apartheid, acompanhando o trajeto espacial e afetivo de mulheres lésbicas negras pela cidade. Também nessa reflexão, enquadramentos binários são desafiados por vidas precárias, mas profundamente criativas e resistentes.

Esse conjunto de reflexões se encerra com dois trabalhos etnográficos de longa duração. As antropólogas Denise Dias Barros e Esmeralda Mariano ampliam nosso olhar para o continente africano no artigo "Experiências que tangenciam o (in)visível e a mobilidade: etnografias em diálogo" analisando de modo comparado experiências ligadas à loucura, à incapacidade reprodutiva, à migração e a um conjunto de dinâmicas de saberes endógenos em situações de crise e sofrimento individual e social entre os Dogon (no Mali) e os Tsonga (no sul de Moçambique).

Fechamos, assim, com uma abertura para novos desafios à perspectiva comparada. 


\section{Para finalizar}

Iniciamos esta pesquisa sem imaginar as transformações radicais e desafios que o Brasil e o mundo iriam enfrentar. Ao ser formulado, o projeto estava inscrito em um quadro amplo e complexo relativo à experiência de redemocratização em curso na África do Sul, Moçambique e Brasil, visando à ampliação do diálogo Sul-Sul.

O projeto PROÁFRICA termina evidenciando os limites e dilemas dessas democracias. As eleições sul-africanas para a presidência da República mostraram a perda de espaço do Congresso Nacional Africano, que precisou ceder um número significativo de cadeiras no parlamento. Mesmo tendo conseguido produzir uma classe média negra, há nichos de desigualdade não resolvidos pelo partido de Nelson Mandela. A Comissão de Verdade e Reconciliação que enfrentou os crimes do regime do apartheid e foi concebida como uma tecnologia social elaborada para sua superação foi uma importante forma de ressignificar e reocupar uma das mais violentas políticas de terror da contemporaneidade (MOUTINHO, 2012), que, entretanto, esbarrou em uma série de limitações econômicas. Seu legado vem sendo questionado na última década, especialmente por jovens negros, como mostra o artigo de Paulo Sérgio da Costa NEVES et al. (2019) nesta Seção Temática. Importantes elementos dessa dramática desigualdade já estavam sinalizados em tocante análise de Zethu MATEBENI (2017), publicada no Brasil. Em Moçambique, o fantasma da guerra segue à espreita em várias situações, evidenciando uma experiência inconclusa de paz, como nos mostra Omar Ribeiro THOMAZ (2019). Se rumores disseminam a possibilidade de uma guerra, o que dizer do extremismo no Brasil, país do Sul Global, especialmente ameaçado em seu processo democrático? O avanço dos discursos de ódio, que revelou uma extrema-direita fundamentalista (Esther Solano GALLEGO, 2018), que de muitas maneiras vem ressecando a legitimidade de debates e a partilha de pontos de vista, tem legitimado múltiplas formas de violência na esfera pública, especialmente, contra aqueles que têm um corpo-alvo, naturalizando-as: negras e negros, trans, lésbicas e gays, mulheres.

Muito temos aprendido e muito temos compartilhado. No momento em que fecho esta apresentação, leio nos jornais sul-africanos que ostentar em público a bandeira do apartheid passará a ser considerado um crime. A gestão das posições extremistas e das tendências enraizadas de totalitarismo (Lilia SCHWARCZ, 2019) são um aprendizado para o Brasil e o mundo atual. Que os textos que compõem esta coletânea sejam, para as leitoras e leitores, tão interessantes como foi, para as autoras e autores, o processo mais amplo da pesquisa.

\section{Referências}

BARROS, Denise Dias; MARIANO, Esmeralda. "Experiências que tangenciam o (in)visível e a mobilidade: etnografias em diálogo". Revista Estudos Feministas, v. 27, n. 3, e66982, 2019.

BRAGA, Carla. “'Machamba não é trabalho!': HIV/SIDA e Produção Agrícola no centro de Moçambique”. Revista Estudos Feministas, v. 27, n. 3, e67175, 2019.

DÖPCKE, Wolfgang. "Uma nova política exterior depois do apartheid? - Reflexões sobre as relações regionais da África do Sul, 1974-1998”. Revista Brasileira de Política Internacional, v. 41, n. 1, p. 132-160, 1998.

CABAÇO, José Luís. Moçambique: identidades, colonialismo e libertação. São Paulo: EDUNESP, 2009.

CNPq. Geral. Programas. "Cooperação Internacional”, PROÁFRICA. Disponível em http://memoria. cnpq.br/proafrica. Acesso em 01/06/2019.

GALLEGO, Esther Solano. "O ódio como política: a reinvenção das direitas no Brasil". São Paulo: Boitempo, 2018.

GEOCAPES. Distribuição de Bolsistas da CAPES no Exterior 2016, 06/07/201 7. Disponível em https:// geocapes.capes.gov.br/geocapes/. Acesso em 01/06/2019.

HOLLAND-MUTER, Susan. "Making place, making home: lesbian queer world-making in Cape Town". Revista Estudos Feministas, v. 27, n. 3, e67311, 2019.

LIBERATO, Rita Simone; MOUTINHO, Laura; NORONHA, Isabel; BAGNOL, Brigitte. "Soberania Alimentar no Machimbombo e na aldeia: gênero na perspectiva Sul-Sul". Revista Estudos Feministas, v. 27, n. 3, e66961, 2019.

LOPES, Pedro. "Deficiência como categoria do Sul Global: primeiras aproximações com a África do Sul”. Revista Estudos Feministas, v. 27, n. 3, e66923, 2019. 
MATEBENI, Zethu. "Perspectivas do Sul sobre relações de gênero e sexualidades: uma intervenção queer". Revista de Antropologia, São Paulo, v. 60, n. 3, p. 26-44, dez. 2017. DOI: 10.1 1606/21790892.ra.2017.141826.

MOMPLÉ, Lília. Neighbours. Maputo: Edição da autora, 2008.

MOUTINHO, Laura. Razão, "Cor" e Desejo: uma análise comparativa sobre relacionamentos afetivosexuais "inter-raciais" no Brasil e na África do Sul. São Paulo: EDUnesp, 2004.

MOUTINHO, Laura. "Sobre danos, dores e reparações: The Moral Regeneration Movement-controvérsias morais e tensões religiosas na ordem democrática sul-africana". In: TRAJANO FILHO, Wilson (Org.). Travessias antropológicas: estudos em contextos africanos. Brasília: ABA, 2012. p. 10-36.

MOUTINHO, Laura; CARRARA, Sergio (Orgs.). Dossiê Raça e Sexualidade em Diferentes Contextos. 35. ed. Campinas: EDUnicamp, 2010 a.

MOUTINHO, Laura; CARRARA, Sergio (Orgs.). "Special Section: Race and Sexuality in Different National Contexts - Brazil and South Africa". Sexuality Research and Social Policy, Nova York, Springer, v. 7, n. 4, 2010b.

MOUTINHO, Laura; CARRARA, Sérgio. "Dossiê Raça, Sexualidade em Diferentes Contextos Nacionais - Apresentação". Cadernos Pagu, Campinas, UNICAMP, v. 35, p. 1-26, 2010c. DOI: 10.1590/S010483332010000200002 .

MOUTINHO, Laura; TRAJANO FILHO, Wilson; LOBO, Andrea (Orgs.). "Dossiê - Olhares Cruzados para a África: Trânsitos e Mediações”. Revista de Antropologia. 60. ed. São Paulo: SIBI/USP, 2017.

NEVES, Paulo Sérgio da Costa; MOUTINHO, Laura; SCHWARCZ, Lilia. "Herança colonial confrontada: reflexões sobre África do Sul, Brasil e Estados Unidos”. Revista Estudos Feministas, v. 27, n. 3, e66960, 2019.

PASSADOR, Luiz Henrique. Guerrear, casar, pacificar, curar: o universo da tradição e a experiência com o HIVIAids no distrito de Homoíne, Sul de Moçambique. 201 1. Tese (Doutorado em Antropologia Social), Campinas, Unicamp, 2011.

PIMENTA, Denise; MOUTINHO, Laura (Orgs.). "África no plural: um dossiê". Cadernos de Campo: Revista de Ciências Sociais, Araraquara, UNESP/FCLAR, v. 23, 2017.

SCHWARCZ, Lilia Moritz. Sobre o autoritarismo brasileiro. São Paulo: Companhia das Letras, 2019.

STOLER, Ann Laura. Carnal Knowledge and Imperial power: Race and the Intimate in Colonial Rule. Berkeley: University of California Press, 2002.

TIRIBA, Thais. "Sugar relationships: sexo, afeto e consumo na África do Sul e no Brasil". Revista Estudos Feministas, v. 27, n. 3, e66921, 2019.

THOMAZ, Omar Ribeiro. "O tempo e o medo: a longa duração da guerra em Moçambique". Outros Tempos, v. 15, p. 88-97, 2018. DOI: 10.18817/ot.v15i26.656.

VIDAL, Dominique "A Nova era das migrações moçambicanas em Joanesburgo". In: BESSERMAN, Helena. Saúde e direitos humanos, ano 5, n. 5, Brasília, Ministério da Saúde; Fundação Oswaldo Cruz; Núcleo de Estudos em Direitos Humanos e Saúde, 2009.

Laura Moutinho (Imoutinho@usp.br) é Livre-Docente do Departamento de Antropologia e do Programa de Pós-Graduação em Antropologia (PPGAS), ambos da USP, e doutora em Antropologia Cultural pela UFRJ. Realizou Pós-Doutorado na Universidade de Princeton, é bolsista produtividade nível $1 \mathrm{D}$ do CNPq, editora da Revista de Antropologia e coordenadora da Comissão Projeto Editorial da Associação Brasileira de Antropologia (ABA).

\section{COMO CITAR ESSE ARTIGO DE ACORDO COM AS NORMAS DA REVISTA}

MOUTINHO, Laura. "Cooperação internacional, parcerias acadêmicas e afeto na perspectiva SulSul”. Revista Estudos Feministas, Florianópolis, v. 27, n. 3, e67310, 2019. 


\section{CONTRIBUIÇÃO DE AUTORIA}

Não se aplica.

\section{FINANCIAMENTO}

Edital PROÁFRICA CNPq: "A vizinhança nas entrelinhas: alianças e conflitos, trocas (des)iguais e cooperação entre Moçambique e África do Sul" (projeto selecionado na Chamada MCTI/CNPq n 46/2014 - Programa de Cooperação em Ciência, Tecnologia e Inovação com Países da África PROÁFRICA) e bolsa produtividade em pesquisa CNPq ID; CAPES (através de bolsa de estudos para doutorandos que participaram do projeto PROÁFRICA/CNPq); FAPESP (através de bolsas de estudos para pós-graduandos que participaram do projeto PROÁFRICA, bem como pelo financiamento do Simpósio "Olhares cruzados para a África: trânsitos e mediações", realizado na USP e na 30a RBA/UFPB, 2016); FAPITEC através de bolsa de doutorado; SESC-Formação - São Paulo com o apoio para o seminário final. A pesquisa contou ainda com o financiamento do Programa de Pós-Graduação em Antropologia da USP.

\section{CONSENTIMENTO DE USO DE IMAGEM}

Não se aplica.

\section{APROVAÇÃO DE COMITÊ DE ÉTICA EM PESQUISA}

Não se aplica.

\section{CONFLITO DE INTERESSES}

Não se aplica.

\section{LICENÇA DE USO}

Este artigo está licenciado sob a Licença Creative Commons CC-BY International. Com essa licença você pode compartilhar, adaptar, criar para qualquer fim, desde que atribua a autoria da obra.

\section{HISTÓRICO}

Recebido em 30/08/2019

Aprovado em 06/09/2019

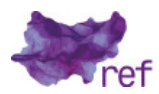

